\title{
MICROWAVE-ASSISTED EXTRACTION OF BIOACTIVE COMPOUNDS
}

FROM SEEDS OF MILK THISTLE, BLACK CUMIN AND CORIANDER

\section{MAGDALENA MAŁYSA-PAŚKO, MARCIN ŁUKASIEWICZ, PIOTR JAKUBOWSKI}

\author{
University of Agriculture in Krakow, Department of Food Technology, \\ ul. Balicka 122, 30-149 Krakow, Poland \\ e-mail: malysamagdalena@gmail.com
}

\begin{abstract}
The aim of the work was to compare the microwave-assisted extraction of coriander, black cumin and milk thistle seeds with the conventional process of extraction. Before the extraction material was crumbled, sieved and defatted. Obtained extracts were analyzed by means of the content of the antioxidants using ABTS, DPPH, Folin - Ciocalteu methods as well as the content of silibinin by HPLC (in case of milk thistle). By using these methods the content of reducing compounds, ability to scavenge free radicals and antioxidant capacity was evaluated in each case. It was shown that for the black cumin and milk thistle more effective was microwave extraction, but for the coriander conventional seems to be better. Extracts of black cumin and milk thistle obtained by microwave extraction have higher concentration of antioxidant compounds as compared to extracts from coriander. In case of coriander most effective a conventional extraction have been designated as more effective one.
\end{abstract}

KEYWORDS

Microwave extraction, milk thistle, coriander, black cumin, conventional extraction, antioxidant compounds

\section{Introduction}

In the last 20 years the demand for medicinal plants in Europe has increased. Countries, where it occupies a significant part of entire market are: Germany (42\%), France (25\%) and Italy (9\%) [Marušk et al. 2010]. In other countries including Poland production of medicines based on medicinal plants has taken place as well. Currently it can be seen the growing interest on the field of: supplements, cosmetics and drug production [Jambor 2007]. Herbal preparations available on market are largely produced by many manufacturers.

Milk thistle (Silybum marianum Gaert L.) is annual and biennial plant grown mainly in the Northern Africa. It occurs wild across Europe, North Africa, the Americas and Australia. Its heights ranges from $70 \mathrm{~cm}$ up to $2 \mathrm{~m}$ depending on the climatic conditions [Andrzejewska and Skinner 2006]. The leaves are dark and shiny. Flowers can be in shades of purple and red. Fruits contain a flavonoid compounds commonly referred as silimarin [Alvarez et al. 2003]. The term silimarina includes dihydroflavonol taxifolin and flavanolignins- silibinin, isosilibinin, silidianin and silichristin. 
Coriander (Coriandrum sativum L.) naturally grows in the Middle East and the Mediterranean. It belongs to the Umbelliferae family. Coriander is grown mainly in: India, China, Georgia, Russia and Central Europe [Kozłowska and Ziarno 2012]. Coriander is an annual plant, reaches up to $140 \mathrm{~cm}$ in height during the flowering period. It has a slightly branched root. It is grown mainly because of the seeds (fruits), which are rich in essential oils [Kozłowska and Ziarno 2012]. Coriander seeds contain approximately: $34 \%$ water, $21 \%$ fat, $14 \%$ protein compounds, $22 \%$ cellulose, $7 \%$ mineral salts and $2 \%$ essential oils. In the coriander seeds fatty acids, among which is the most petroselinic acid are presented. [Kozłowska and Ziarno 2012].

Black cumin (Nigella sativa) belongs to the family Ranunculaceae. The plant naturally grows in: India, Pakistan, Afghanistan, Saudi Arabia and Turkey. It grows to a height of $20-30 \mathrm{~cm}$. Black cumin flowers are delicate with a typical pale blue or white with a few flakes. Fruits have an oblong shape resembling a capsule, in which inside three to seven interconnected seeds are placed [Balbay et al. 2012]. Black cumin seeds contain a lot of alkaloids including: nigellamine A1-A5, B1, B2 and C (diterpene alkaloids), nigelline, nigellimine (isoquinoline alkaloids) and very rare in the world of plants nigellidine and nigellicine (indazoles alkaloids). In addition, it is rich in essential oils and flavonoids. Seeds contain from $0.4-2.5 \%$ essential oils and $30-50 \%$ fat. With occurring in these essential oils are worth mentioning for example: carvone, trans-anethole and characteristic tymochinon, tymohydrochinon and ditymochinon [Mańkowska and Bylka 2009].

Microwave Assisted Extraction is mainly used for analysis of samples of solids. This technique is based on absorption of electromagnetic radiation by particles of the extractant. The effectiveness of this method is associated with a different heat transfer process. Electromagnetic waves in the microwave frequency can transmit heat in two ways. The first one is related to the polarization dipole. Dipole moment molecules with greater or different from zero inside the electrical field set up in accordance with his direction and return (polarization). In the second case microwave assisted extraction is related to the mobility of ions (ionic conductivity). Heat is the result of friction between the silver ions and the solution. For this method, the best solvents whose dipole moment is not zero are for mainly: ethanol, water and acetone [Stepnowski et al. 2010].

\section{Materials and methods}

\subsection{Materials}

The experimental materials were the fruits of milk thistle (Aroma of Nature, Krzysztof Kowalewski Strzelce Krajeńskie, Poland),black cumin seeds (Ekogram, Zielonka, Poland) and coriander seeds (RW. Record, Joseph Szwajkowski, Żelazków, Poland) purchased on Polish market. The plant material was grinded and sieved through mechanical sieves (ø $0,47 \mathrm{~mm})$. Next material was degreased and was subjected to extraction.

\subsection{Extraction procedure}

As extractants a 99,8\% ethanol diluted with distilled water to give solutions of 40, 65 and 90\% (v/v) was used. In the extraction vessels (for $100 \mathrm{~cm}^{3}$ ) $2 \mathrm{~g}$ of the sample were weighed, and $60 \mathrm{~cm}^{3}$ of extractant were added. Conventional extraction was carried out in a water bath and microwave extraction was carried out in microwave reactor (RM 800PC, Plazmotronika, Wroclaw). The temperature control I both kind of experiments was performed using fiberoptic sensor Reflex RFX-2 (Neoptix, Canada)

\subsection{Planning of the experiment}

Effect of extraction method on the contents of the reducing compounds, antioxidant capacity and capacity of radials scavenging was tested for three factors (temperature/power extractant concentration and time) using response surface methodology. Number of experiments was set to 20. 
Tab. 1 Design of experiment for conventional extraction of black cumin, coriander milk thistle.

\begin{tabular}{|c|c|c|c|}
\hline ID & $\begin{array}{c}\text { Temperature } \\
{\left[{ }^{\circ} \mathbf{C}\right]}\end{array}$ & $\begin{array}{c}\text { Time } \\
{[\mathbf{m i n}]}\end{array}$ & $\begin{array}{c}\text { Concentration of } \\
\text { EtOH [\%] }\end{array}$ \\
\hline 1 & 30 & 60 & 40 \\
\hline 3 & 30 & 180 & 40 \\
\hline 9 & 30 & 120 & 65 \\
\hline 5 & 30 & 60 & 90 \\
\hline 7 & 30 & 180 & 90 \\
\hline 13 & 45 & 120 & 40 \\
\hline 11 & 45 & 60 & 65 \\
\hline 12 & 45 & 180 & 65 \\
\hline 15 & 45 & 120 & 65 \\
\hline 16 & 45 & 120 & 65 \\
\hline 17 & 45 & 120 & 65 \\
\hline 18 & 45 & 120 & 65 \\
\hline 19 & 45 & 120 & 65 \\
\hline 20 & 45 & 120 & 65 \\
\hline 14 & 45 & 120 & 90 \\
\hline 2 & 60 & 60 & 40 \\
\hline 4 & 60 & 180 & 40 \\
\hline 10 & 60 & 120 & 65 \\
\hline 6 & 60 & 60 & 90 \\
\hline 8 & 60 & 180 & 90 \\
\hline
\end{tabular}

Tab. 2 Design of experiment for microwave extraction of black cumin, coriander milk thistle.

\begin{tabular}{|c|c|c|c|}
\hline $\begin{array}{c}\text { Number of } \\
\text { experiment }\end{array}$ & $\begin{array}{c}\text { MW Power } \\
{[\mathbf{W}]}\end{array}$ & $\begin{array}{c}\text { Time } \\
{[\mathbf{m i n}]}\end{array}$ & $\begin{array}{c}\text { Concetration EtOH } \\
{[\%]}\end{array}$ \\
\hline 1 & 7 & 10 & 40 \\
\hline 3 & 7 & 30 & 40 \\
\hline 9 & 7 & 20 & 65 \\
\hline 5 & 7 & 10 & 90 \\
\hline 7 & 7 & 30 & 90 \\
\hline 13 & 14 & 20 & 40 \\
\hline 11 & 14 & 10 & 65 \\
\hline 12 & 14 & 30 & 65 \\
\hline 15 & 14 & 20 & 65 \\
\hline 16 & 14 & 20 & 65 \\
\hline 17 & 14 & 20 & 65 \\
\hline 18 & 14 & 20 & 65 \\
\hline 19 & 14 & 20 & 65 \\
\hline 20 & 14 & 20 & 65 \\
\hline 14 & 14 & 20 & 90 \\
\hline 2 & 21 & 10 & 40 \\
\hline 4 & 21 & 30 & 40 \\
\hline 10 & 21 & 20 & 65 \\
\hline 6 & 21 & 10 & 90 \\
\hline 8 & 21 & 30 & 90 \\
\hline & & & \\
\hline
\end{tabular}




\subsection{Analytical Methods}

\section{Determination of reducing compounds}

The content of the reducing compounds was performed by Folin-Ciocalteu reagent [Singleton et al. 1999]. To prepare a standard curve a gallic acid solution was used in concentration of $50 \mathrm{mg} / 100 \mathrm{~cm}^{3}$.

$\underline{\text { Radical scavenging capacity }}$

The capacity of radical scavenging was performed by DPPH reagent [Kowalski 2013].

Antioxidant capacity

The antioxidant capacity was marked by ABTS reagent [Re et al. 1999].

$\underline{\text { Silibinin content }}$

The content of silibini was analysed using by using HPLC (High Pressure Liquid Chromatography) [Kvasnička et al. 2003]. The analysis was performed on a Lichrospher RP C18 (250 x $4 \mathrm{~mm}$, particle size: 5 .mu.m) column at $290 \mathrm{~nm}$ UV detection. The flow rate of the mobile phase was $1 \mathrm{ml} / \mathrm{min}$ and sample volume injected into the column $10 \mu \mathrm{l}$.

\section{Results and discussion}

\section{Milk thistle}

Comparing the results obtained in the two different extractions types for milk thistle it can be seen that at the lowest microwave power the more reducing compounds in the extract (Fig. 1A and D) and higher antioxidant capacity (Fig. 1B and E) were. Comparing those results to lowest temperature used during the conventional extraction more bioactive compounds were extracted by means of DPPH method. The results of the content of reducing compounds, and the ability to scavenge free radicals obtained at a temperature of $45{ }^{\circ} \mathrm{C}$ and at $14 \mathrm{~W}$ and $21 \mathrm{~W}$ and $60{ }^{\circ} \mathrm{C}$ in most cases, are higher for the conventional extraction, but the antioxidant capacity (Fig. $1 \mathrm{G}$ and $\mathrm{H}$ ) is significantly higher in case of microwave assisted process. The highest concentration of slibininin (Fig. 1C and F) of concentration of the compound was observed using the microwave extraction at the lowest power. For medium and the highest power the opposite situation was observed, higher silibinin concentration was determined in extracts in medium and the highest temperature from the conventional method (with the exception extract obtained in conditions $14 \mathrm{~W} 20 \mathrm{~min} 40 \%$ ). The results obtained in the highest tested temperature and power confirms that the highest antioxidant capacity of the extracts was obtained during the microwave extraction. Significantly better results are extracts, in which tests the ability of scavenging, wherein the highest values characterized by the extracts obtained by conventional extraction.

Equivocal results are for the concentration of reducing compounds, as only an eluent having a concentration of $65 \%$ eluent more polyphenols obtained in the course of the microwave extraction. 
A

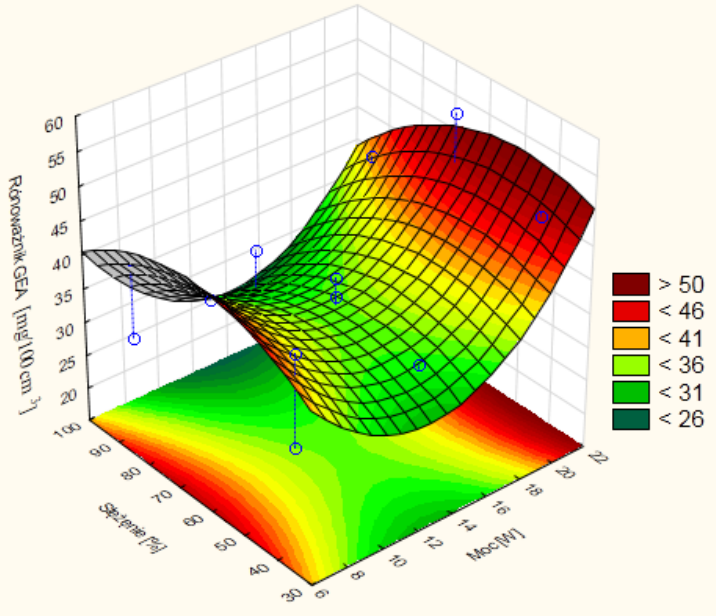

C
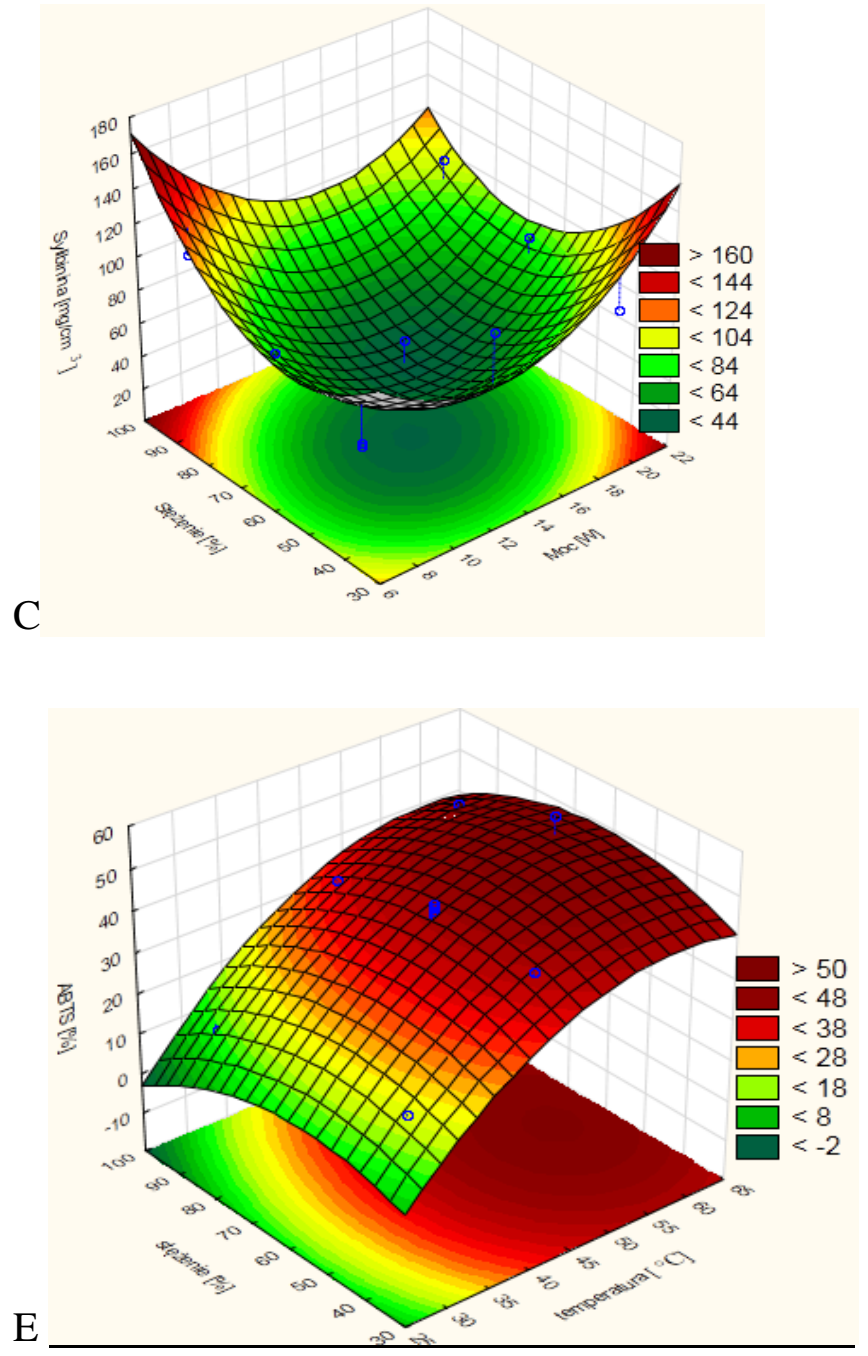

B

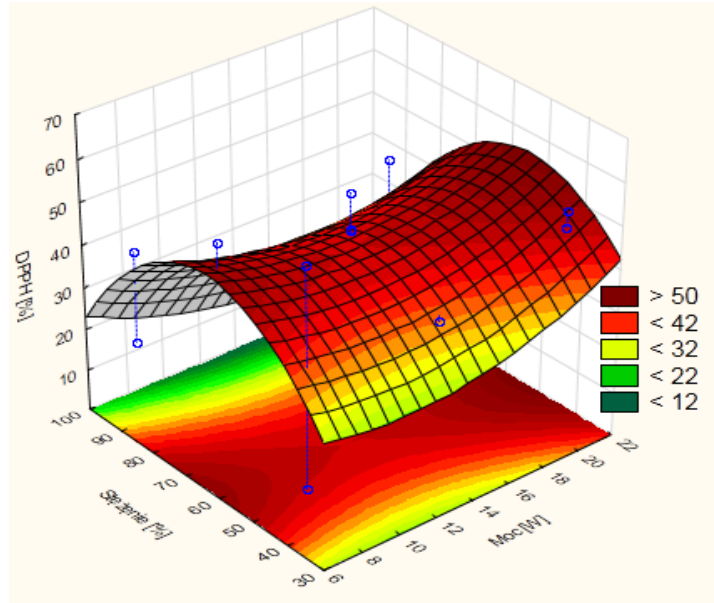

D
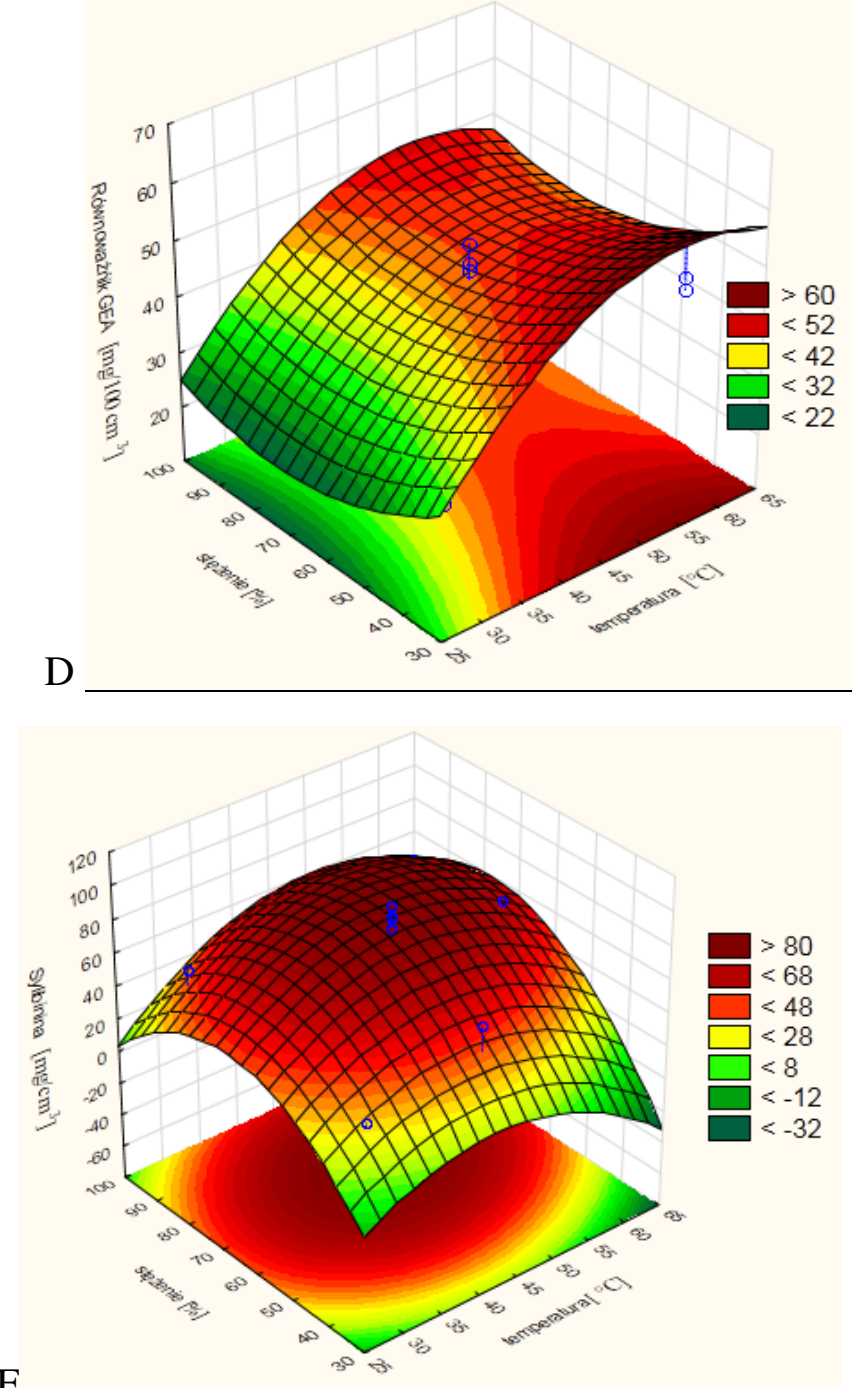

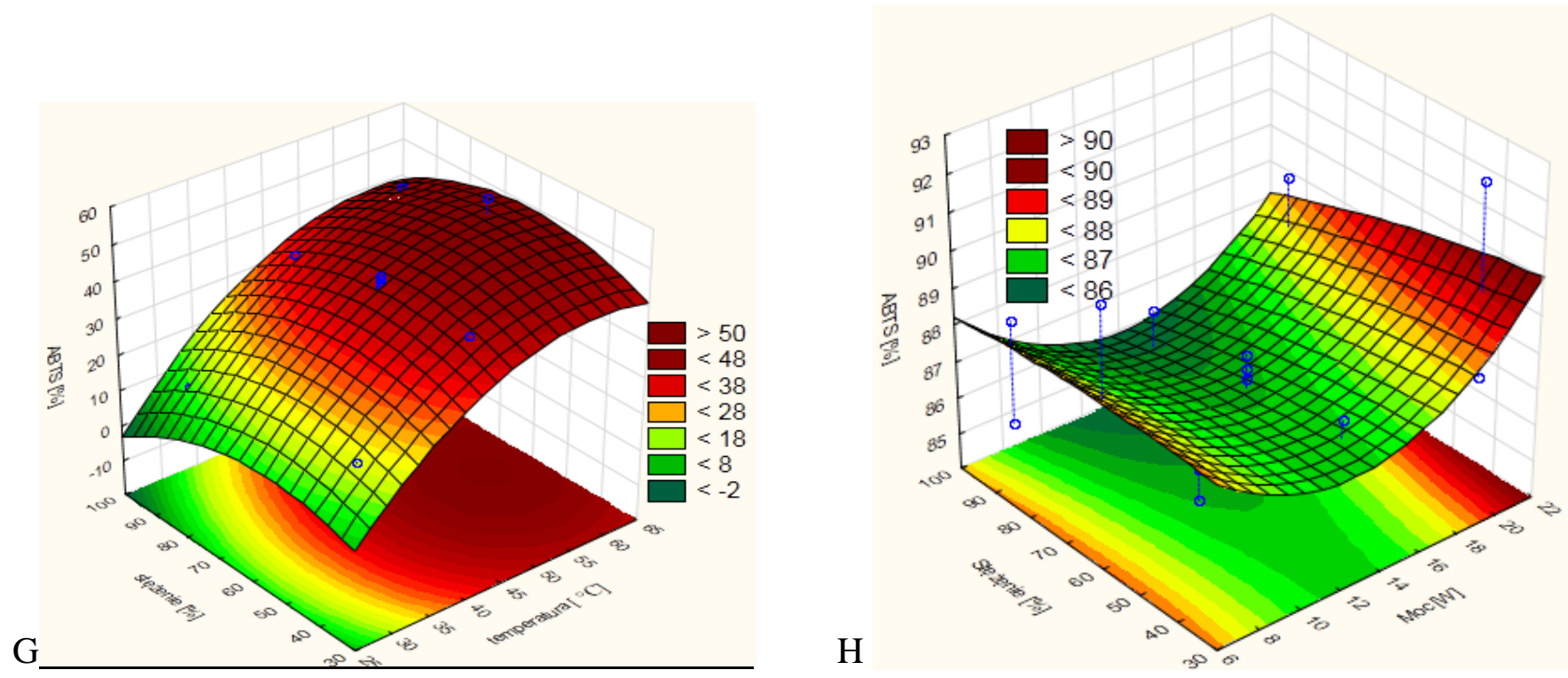

Fig. 1 Surface plot:

A. for changes the concentration of reducing compounds according power and concentration of eluent obtained in extracts from milk thistle by microwave extraction in the medium time $20 \mathrm{~min}$

B. for changes the radical scavenging capacity according power and concentration of ethanol obtained in extracts from milk thistle by microwave extraction in the medium time $20 \mathrm{~min}$

C. for changes the concentration of silibinin according power and concentration of ethanol in extracts from milk thistle obtained by microwave extraction in the medium time $20 \mathrm{~min}$

D. for changes the concentration of reducing compounds according temperature and concentration of eluent obtained in extracts from milk thistle by conventional extraction in the medium time $120 \mathrm{~min}$

E. for changes the radical scavenging capacity according temperature and concentration of ethanol obtained in extracts from milk thistle by conventional extraction by medium time $120 \mathrm{~min}$

F. for changes the concentration of silibinin according temperature and concentration of eluent obtained in extracts from milk thistle by conventional extraction by medium time $120 \mathrm{~min}$

G. for changes the antioxidant capacity according temperature and concentration of eluent obtained in extracts from milk thistle by conventional extraction in medium time $120 \mathrm{~min}$

H. for changes the antioxidant capacity according power and concentration of ethanol obtained in extracts from milk thistle by microwave extraction in medium time $20 \mathrm{~min}$

Black cumin

Comparing the scores, it turned out that the results obtained for microwave extraction were significantly higher than conventional. However, in the experience of the content of reducing compounds (Fig. 2A and C) in the lowest power/temperature extraction oven had higher scores (with the exception extract of 90\% eluent, time: $30 \mathrm{~min}$ ), the medium power/temperature higher was the results for extracts from microwave assisted extraction. The highest power/temperature results were varied, it means that for 40 and $65 \%$ alcohol higher for the microwave extraction, but at $90 \%$ in 10 min higher score had the conventional extraction, and with a longer oven. In this study the ability of scavenging (Fig. 2B and D) at the lowest power/temperature for 90 and $40 \%$ alcohol higher score for conventional extraction and $65 \%$ higher for the microwaves. The average power/temperature results were too disparate be repeated in this part of the study. However, in the highest power/temperature for $40 \%$ of the solvent extraction had higher scores oven, and at 65 and $90 \%$ conventional. 


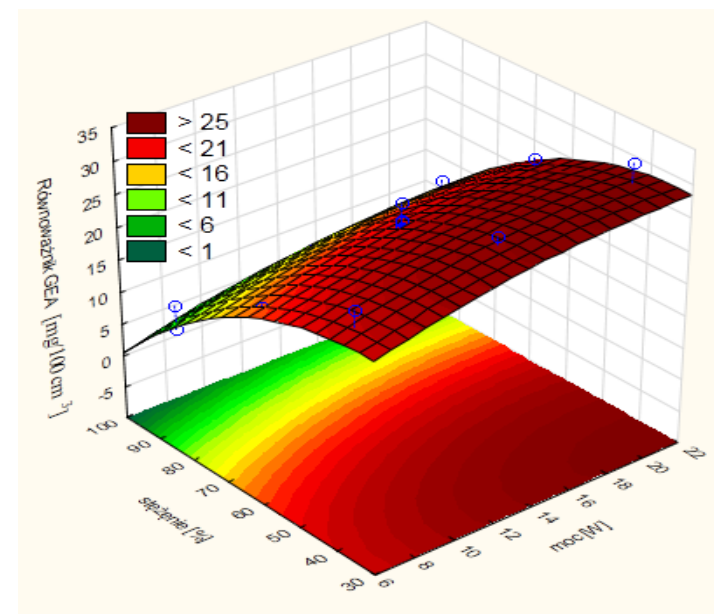

A

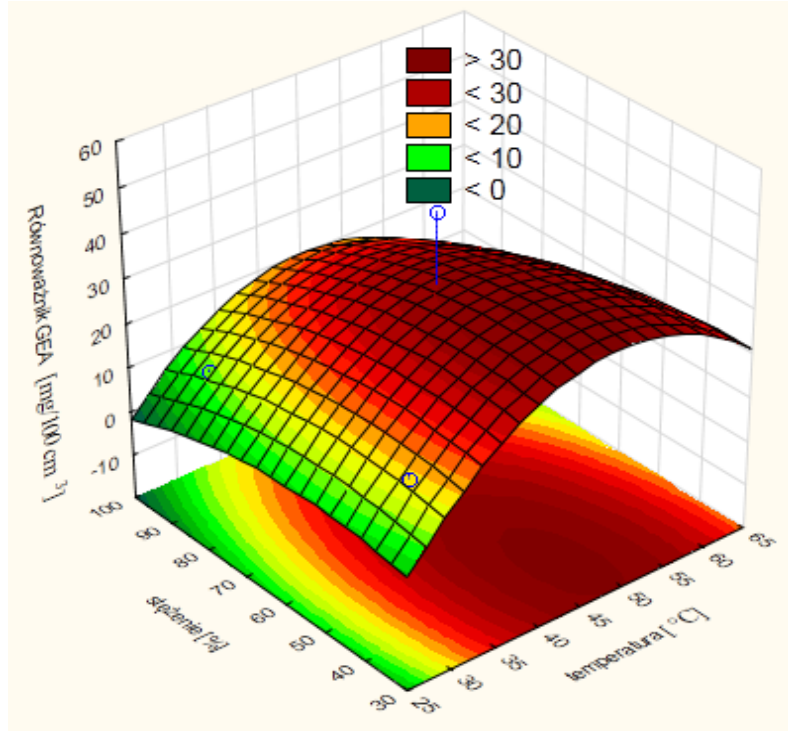

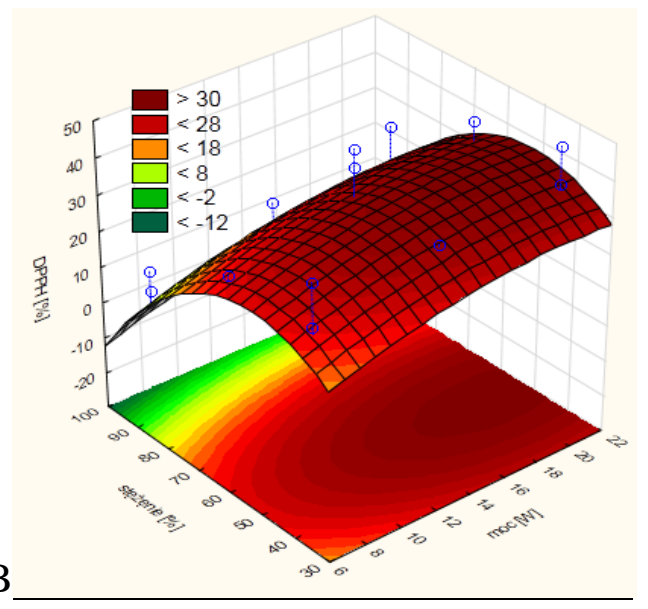

B

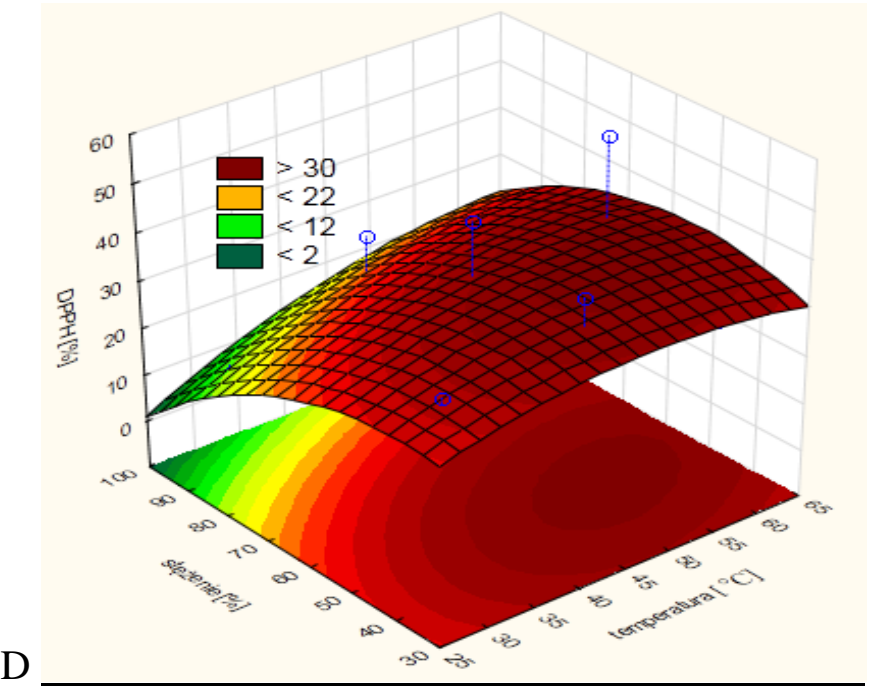

Fig. 2 Surface plot:

A. for changes the concentration of reducing compounds according power and concentration of eluent for extracts from black cumin obtained by microwave extraction in medium time $20 \mathrm{~min}$

B. for changes the radical scavenging capacity according concentration of ethanol and power for extract from black cumin obtained by microwave extraction in medium time $20 \mathrm{~min}$

C. for changes the concentration of reducing compounds according temperature and the concentration of eluent for extracts from black cumin by conventional extraction in medium time $120 \mathrm{~min}$

D. for changes the radical scavenging capacity according temperature and the concentration of eluent for extracts from black cumin by conventional extraction in medium time $120 \mathrm{~min}$

\section{Coriander}

The lowest median (with the exception extraction 120 minutes with $65 \%$ eluent $45{ }^{\circ} \mathrm{C}$ ) and high (except 10 minutes of extraction, $40 \%$, solvent 21) at/under the extracts obtained by conventional extraction had a higher concentration of phenolic compounds tested with the DPPH (Fig. 3A and C). The results for extracts obtained by extracting the oven was significantly higher when tested for their antioxidant capacity (Fig. 3D and F) using ABTS. The results obtained during tests using the Folin-Ciocalteu at the lowest power/temperature were higher for conventional extraction (Fig. 3B and E). The medium temperature/power for both extraction in the case Folin-Ciocalteu obtained fairly similar results, but a little higher for the 
extraction microwave (except extraction of 120 minutes, $90 \% 45^{\circ} \mathrm{C}$ ). With the highest temperature/power higher scores were the extraction microwave (except extraction of 180 minutes, $90 \%, 60{ }^{\circ} \mathrm{C}$ ).

A

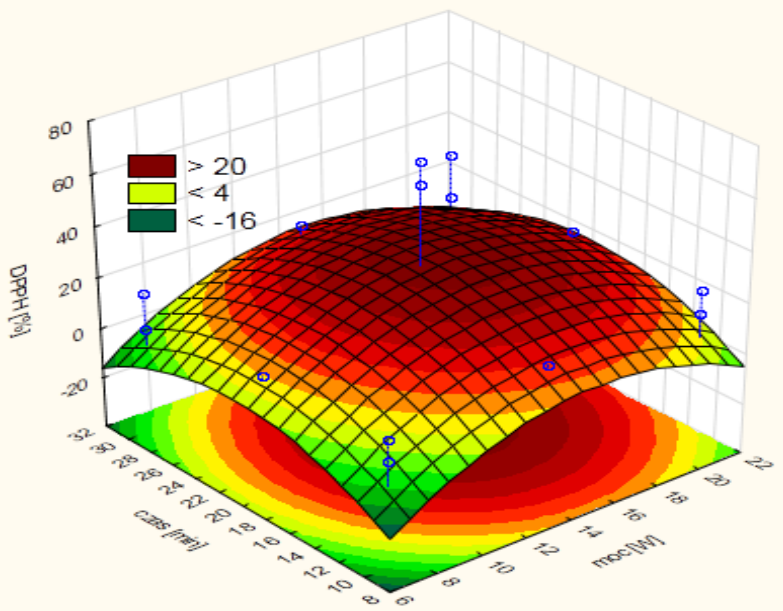

$\mathrm{C}$
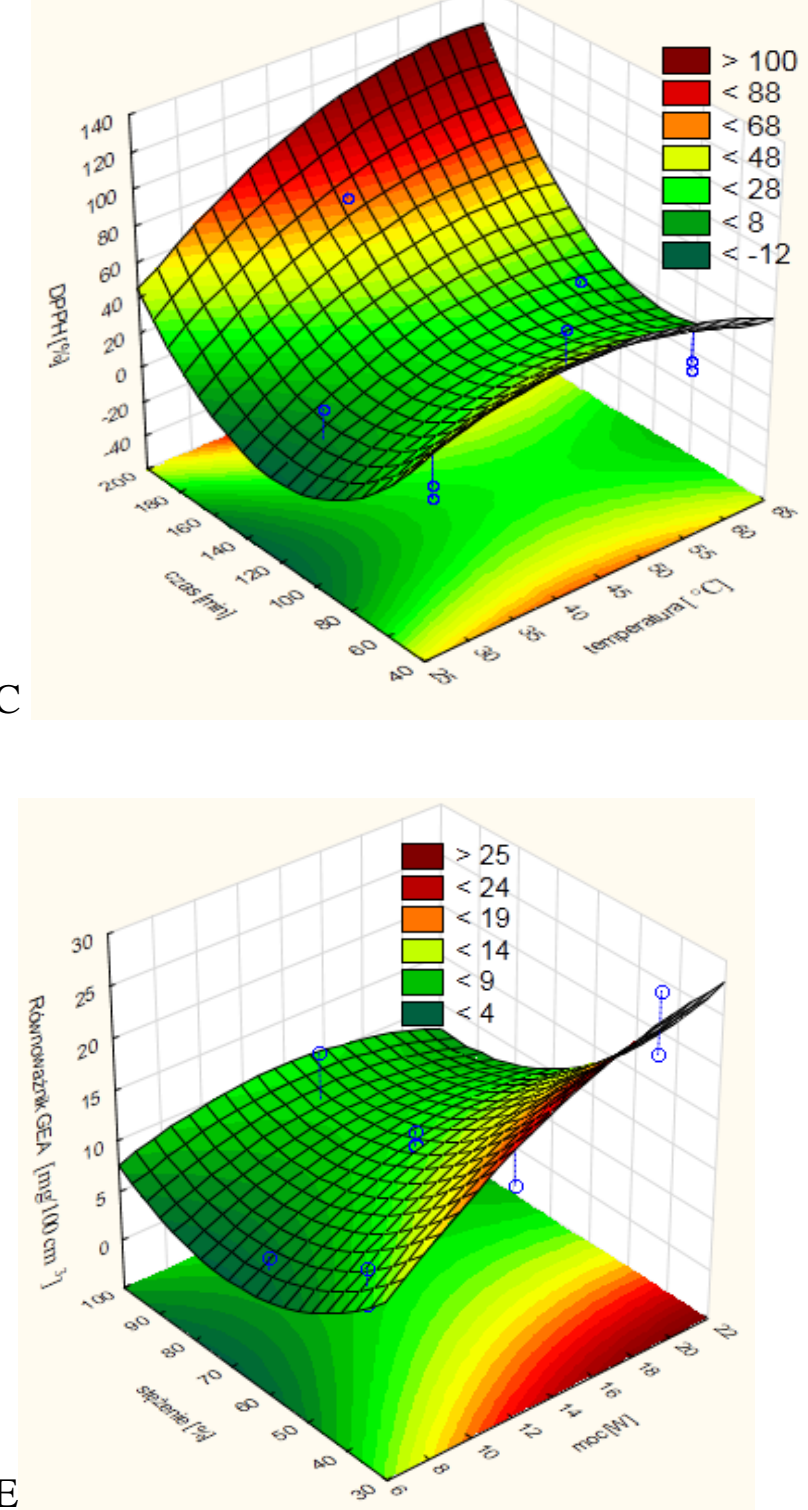

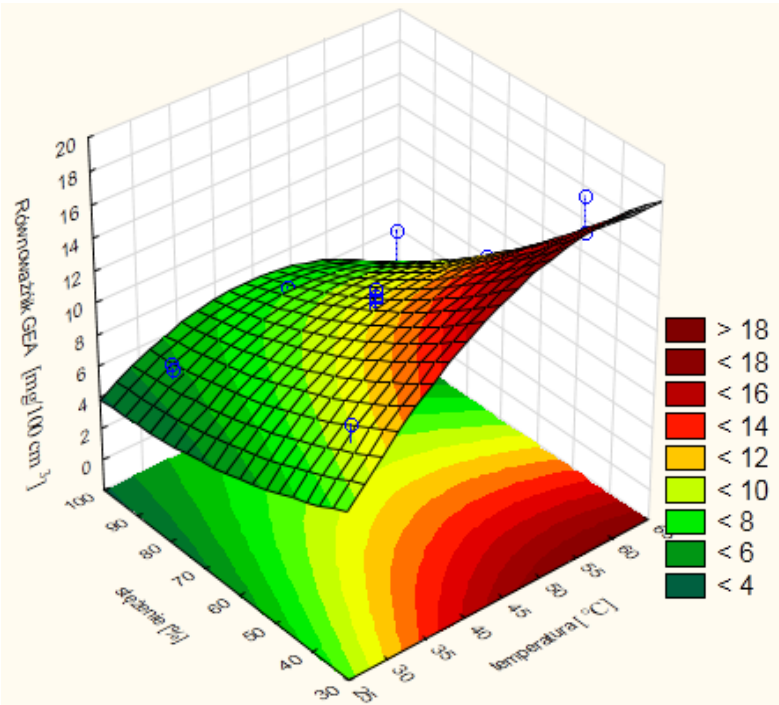

B
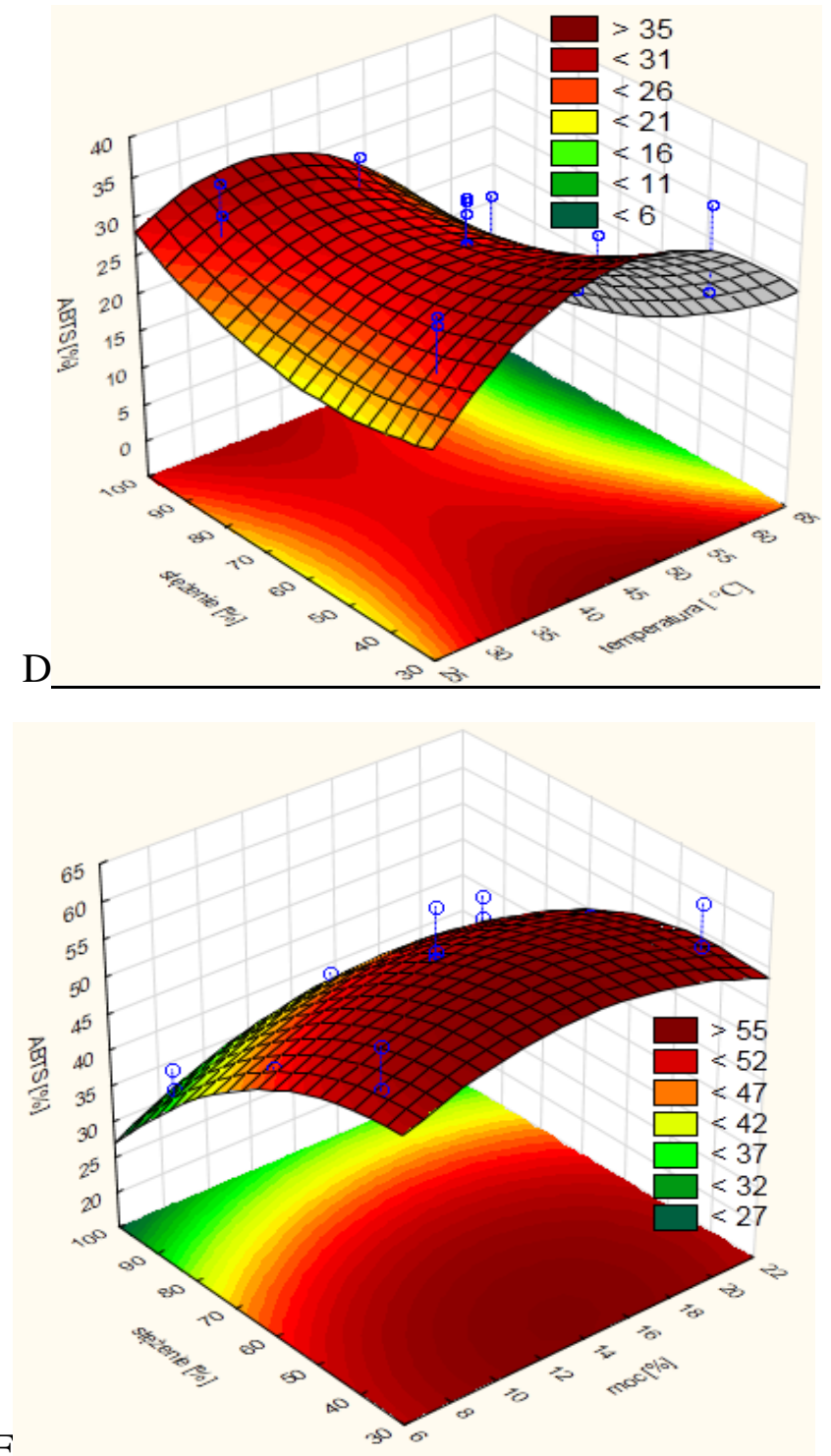

Fig. 3 Surface plot: 
A for changes the radial scavenging capacity according power and time for extracts from coriander obtained by microwave extraction following $65 \%$ concentration of ethanol

B. for changes the concentration of reducing compounds according temperature and concentration of ethanol for extracts from coriander obtained by conventional extraction in medium time $120 \mathrm{~min}$

C. for changes the radial scavenging capacity according temperature and time for extracts from coriander obtained by conventional extraction following $65 \%$ concentration of ethanol

D. for changes the antioxidant capacity according temperature and concentration of ethanol for extracts from coriander obtained by conventional extraction in medium time $120 \mathrm{~min}$

E. for changes the concentration of reducing compounds according power and concentration of ethanol for extracts from coriander obtained by microwave extraction in medium time $20 \mathrm{~min}$

F. for changes the antioxidant capacity according temperature and concentration of ethanol for extracts from coriander obtained by microwave extraction in medium time $20 \mathrm{~min}$

The studies found that in the case of black cumin and milk thistle more reducing compounds and a higher antioxidant capacity (even in the coriander test) was determined in the extracts obtained by microwave assisted extraction. When determining the content of reducing compounds in the extracts of coriander higher concentration of these compounds were extracts obtained by the conventional method (the exceptions being the extracts, in which time the whole process was 180 minutes of extraction solvent $40 \%$ - study reducing compounds). However, in the case of testing the ability of scavenging in extracts from. For black cumin the most important was the temperature/power as the lowest temperature in the extraction of conventional determined greater capacity, but the median scores were significantly lower than for the extraction of the microwave (in the case of extract from milk thistle higher the ability of the extracts were obtained by extracting the microwave). The extracts coriander superior ability extracts were prepared by a conventional method. In the case of extract from milk thistle silibinin higher concentration in the extracts was determined using a microwave extraction. Comparing among themselves all the extracts obtained by the conventional method it can be seen that the highest concentration of reducing compounds, the ability to scavenge free radicals and antioxidant capacity were obtained in extracts of milk thistle (with the exception antioxidant capacity - the highest value obtained in extracts of black cumin). In the extracts obtained by microwaves also the highest results in all studies have extracts from milk thistle (except for the ability to scavenge free radicals at which depending on the process values are sometimes higher for extracts from black cumin). Both extractions were found to be the least effective for coriander.

The highest values of the heating rate have extracts of black cumin and milk thistle (tab. 3), especially when extraction with the highest power $(21 \mathrm{~W})$. This means that heat the fastest, which resulted in the most efficient extraction of bioactive compounds .

Tab. 3 The initial speed for individual experiments

\begin{tabular}{|c|c|c|c|c|}
\hline ID & $\begin{array}{c}\text { Power } \\
{[\mathbf{W}]}\end{array}$ & $\begin{array}{c}\text { Milk thistle } \\
\frac{{ }^{\circ} \mathrm{C}}{\min }\end{array}$ & $\begin{array}{c}\text { Coriander } \\
\frac{{ }^{\circ} \mathrm{C}}{\min }\end{array}$ & $\begin{array}{c}\text { Black cumin } \\
\frac{{ }^{\circ} \mathrm{C}}{\min }\end{array}$ \\
\hline 1 & 7 & 1.51 & 1.51 & 1.56 \\
\hline 2 & 21 & 2.79 & 2.90 & 3.06 \\
\hline 3 & 7 & 1.05 & 0.95 & 0.90 \\
\hline 4 & 21 & 2.11 & 0.94 & 2.25 \\
\hline 5 & 7 & 2.23 & 1.85 & 1.84 \\
\hline 6 & 21 & 3.77 & 3.81 & 3.74 \\
\hline 7 & 7 & 1.57 & 0.98 & 1.34 \\
\hline
\end{tabular}




\begin{tabular}{|c|c|c|c|c|}
\hline 8 & 21 & 2.84 & 2.41 & 2.85 \\
\hline 9 & 7 & 1.46 & 1.30 & 1.22 \\
\hline 10 & 21 & 2.38 & 2.23 & 2.46 \\
\hline 11 & 14 & 2.58 & 2.56 & 2.64 \\
\hline 12 & 14 & 1.61 & 1.34 & 1.56 \\
\hline 13 & 14 & 1.89 & 1.82 & 1.84 \\
\hline 14 & 14 & 2.03 & 1.97 & 2.51 \\
\hline 15 & 14 & 1.87 & 1.89 & 1.87 \\
\hline 16 & 14 & 1.99 & 1.89 & 1.91 \\
\hline 18 & 14 & 1.93 & 1.90 & 1.95 \\
\hline 20 & 14 & 1.87 & 1.85 & 1.97 \\
\hline
\end{tabular}

\section{Conclusions}

1. In the case of black cumin and milk thistle during the microwave and conventional extraction gave significantly more antioxidant compounds as compared extracts from coriander.

2. During conventional extraction of coriander obtained more antioxidant compounds.

3. Comparing both extraction of the most effective in the case of black cumin and milk thistle was a microwave extraction.

4. The most effective extractant in 40 and $65 \%$ aqueous ethanol solutions.

5. As temperature increase during the conventional extraction was extracted much more antioxidant compounds.

6. As heat increase during the microwave extraction was extracted much more antioxidant compounds.

\section{Bibliography}

1. Alvarez Baretto J.F. , Wallace S.N., Carrier J.D., Clausen E.C., 2003. Extraction of nutraceuticals from Milk Thistle, part I Hot water extraction. Applied Biochemistry and Biotechnology, vol. 105 - 108.

2. Andrzejewska J., Skinder Z., 2006. Milk thistle - remarks about the naming , active substances and plant development (Ostropest plamisty - uwagi o nazewnictwie, substancjach czynnych i rozwoju rośliny). Acta Sci. Pol., Agriculture, 5 (1), 5 - 10.

3. Balbay A., Yilmaz K., Omer S., 2012. Drying of black cumin (Nigella sativa) in a microwave assisted drying system and modeling using extreme learning machine. Energy, 44, 352 - 357.

4. Jambor J., 2007. Herbalists in Poland - current state and prospects of development (Zielarstwo w Polsce - stan obecny i perspektywy rozwoju). Borgis - Postępy Fizjoterapii, 2, 78 - 81.

5. Kowalski S., 2013. Changes of antioxidant activity and formation of 5 -hydroxylmethylfurfural in honey during thermal and microwave processing. Food Chemistry, 141 (2), $1378-1382$.

6. Kozlowska M., Ziarno M., 2012.Coriander - composition and application (Kolendra - skład i zastosowanie). Borgis - Postępy Fitoterapii, 2, 108 - 112. 
7. Kvasnička, F., Bíba, B., Ševčík, R., Voldřich, M., Krátká, J., 2003. Analysis of the active components of silymarin. Journal of Chromatography A, 990 (1-2), 239-245.

8. Mańkowska D., Bylka W., 2009. Nigella sativa L. - bioactive compounds, biological activity (Nigella sativa L. - związki czynne, aktywność biologiczna). Herba polonica, 55, 1, 109 - 125.

9. Marušk A., Proscevičius J., Bimbiraitė - Survilienė K., Konryšova O., Ragažinskienė O., Ratautaitė V., 2010. Comparison of phytochemical composition of medicinal plant by means of chromatographic and related techniques. Procedia Chemistry, vol. 1 (2), 83 - 91.

10. Re R., Pellegrini N., Proteggente A., Pannala A., Yang M., Rice - Evans C., 1999. Antioxidant activity applying an improved ABTS radical cation decolorization assay. Free Radic Biology and Medicine, 26, $1231-1237$.

11. Singleton, V. L., Orthofer, R., Lamuela-Raventos, R. M., 1999. Analysis of total phenols and other oxidation substrates and antioxidants by means of Folin-Ciocalteu Reagent. Methods in Enzymology, 299, 152-178.

12. Stepnowski P., Synak E., Szafranek B., Kaczyński Z., 2010. Separation techniques (Techniki separacyjne). Wydawnictwo Uniwersytetu Gdańskiego w Gdańsku. 